\title{
EDITORIAL \\ Monitoring the brain functions: Going back to the future!
}

Neurologically compromised patients have rapid fluctuations in their neurologic status which makes it imperative that monitoring be closely performed. If not detected timely, these sudden changes in the neurologic status may prove irreversible and catastrophic. Therefore, the primary aim of monitoring in the practice of neuroanaesthesia are, (a) quick detection and management of insult of any magnitude to brain and spinal cord, during surgery, positioning or in the intensive care are, (b) improve the patho-physiological understanding of cerebral diseases which helps to institute the rational management, (c) obtain various physiological parameters to guide individualised therapy, and (d) prognostication in critical patients. The brain is highly vulnerable to ischaemic insults because of lack of glucose reserves. Thus, the importance of continuous blood supply to the brain to meet its metabolic demands cannot be overemphasised. The principles of neurocritical care revolve around maintaining the balance between the cerebral metabolic demand and supply, making continuous monitoring of these parameters of immense significance.

Neurophysiologic monitoring has now become an integral part of any neurosurgical procedure. It is now considered to be a part of standard practice in many parts of the world. This, however, may not be true in the Indian scenario as many centres continue to perform neurosurgical procedures without appropriate neurophysiologic monitoring. This could either be due to lack of facilities or trained personnel. Neuromonitoring devices are largely remaining the prerogative of the neurosurgeons and the neurophysiologists; anaesthetists, however, plays a crucial role in its clinical usage and interpretation. It is, therefore, imperative that anaesthetist be aware of the basics of the various neuromonitoring equipment. This special issue is aimed with the purpose that the reviews written by leading neuroanaesthetists in the country would benefit not only the resident doctors but also a practitioner who do not have formal training in neuroanaesthesia. The current issue discusses all possible modalities of neurologic monitoring ranging from the most basic one such as the intracranial pressure monitoring to the most sophisticated ones such as brain microdialysis and functional neuroimaging. Reviewing literature from the recent years, one can clearly witness the increase in the understanding and importance of neurophysiologic monitoring.
With so many monitoring modalities, it is intuitive to question which is the best available monitor? This remains an unanswered question to date. An ideal monitor should be sensitive, specific, minimally invasive, easy to operate and cost-effective. However, one can surely reach a consensus that multimodal monitoring technique is the simplest and unbiased solution. In this context, each new monitor should be considered as an addition and not a substitute. Multimodal monitoring will most likely to be the technique in future. We earlier published an overview of various neuromonitoring modalities related to the critical care. ${ }^{[1]}$ While we take you 'back to the future' with this issue, I'm sure you will enjoy reading the very comprehensively written reviews on various neurophysiologic monitoring systems, as much as we enjoyed preparing it.

\section{Hemanshu Prabhakar}

Department of Neuroanaesthesiology and Critical Care,
AlIMS, New Delhi, India
Address for correspondence:
Dr. Hemanshu Prabhakar,
Department of Neuroanaesthesiology and Critical Care, $7^{\text {th }}$ Floor,
Neurosciences Centre, AIIMS, New Delhi - 110 029, India.
E-mail: prabhakaraiims@yahoo.co.in

\section{REFERENCE}

1. Ristic A, Sutter R, Steiner LA. Current neuromonitoring techniques in critical care. J Neuroanaesth Crit Care 2015;2:97-103.

This is an open access article distributed under the terms of the Creative Commons Attribution-NonCommercial-ShareAlike 3.0 License, which allows others to remix, tweak, and build upon the work non-commercially, as long as the author is credited and the new creations are licensed under the identical terms.

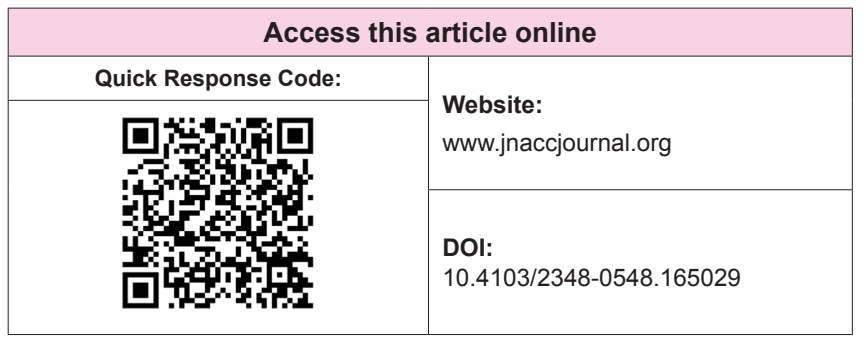

How to cite this article: Prabhakar H. Monitoring the brain functions: Going back to the future!. J Neuroanaesthesiol Crit Care 2015;2:167. 